\title{
Composite Shaftless Roller Design for Conveyor System
}

\author{
Greg Wheatley ${ }^{1 *}$, Mohammad Zaeimi² \\ 1 College of Science and Engineering, James Cook University, QLD 4814 Townsville, 1 James Cook Drive, Australia \\ 2 Department of Mechanical Engineering, University of Guilan, Rasht, 4199613776 Gulian, 5th Kilometer of Persian Gulf Highway, \\ Iran \\ * Corresponding author, e-mail: greg.wheatley@jcu.edu.au
}

Received: 20 November 2020, Accepted: 11 January 2021, Published online: 09 July 2021

\begin{abstract}
Improving the performance of idlers is paramount to the performance of the conveyor system in various industries since belt conveyors can be many kilometers in length and consequently there are a huge number of rollers in use. The key intention of this work is the development of a light-weight composite idler roller. Critical design considerations are strength-to-weight ratio and performance. Most importantly, the design must reduce the weight of the roller as compared to standard steel rollers. The final design provides a significant reduction in weight of about $47 \%$ over that of traditional steel rollers of a similar size.
\end{abstract}

\section{Keywords}

shaftless roller, composite, conveyor system

\section{Introduction}

The most commonly used material handling conveyor system is the belt conveyor [1]. The popularity of belt conveyors is owed to their capability of handling a wide variety of materials and their status as the least expensive powered conveyor. The two most common types of belt conveyors are slider bed conveyors and belt-on-roller (BOR) conveyors. Generally, BOR conveyors are the preferred belt conveyor system for bulk materials handling [2].

BOR conveyors utilize a series of rollers to support and shape the belt [2]. The belt spans between a head pulley and a tail pulley and pulleys allow the belt to bend from the carrying surface (top) to the return side [1]. Movement of the belt is produced by a drive unit, consisting of an electric motor, couplings, and a gearbox, which is connected to the head pulley [3]. Bulk material is deposited on the belt through a loading chute and is transported forwards by the movement of the belt over spatially distributed carrier idler rollers. The material is discharged when it reaches the head pulley, and the un-laden belt travels back towards the tail pulley supported by return idler rollers.

Although belt conveyors are available in a variety of configurations such as flat belt, cleated belt, curved belt, and troughed belt [4], the last one is considered in this work which is the most common type of belt conveyor used in the mining industry. McGuire [1] states that troughed belts are used almost exclusively for bulk material handling (coal, iron ore, sugar) because there is no concern for product orientation. Furthermore, troughed belts have been shown to reduce bulk material losses during transport, as well as the transport capacity of the conveyor.

Typically, troughed belt conveyors are formed using a set of three identical idler rollers [4]. One roller is positioned horizontally, with the other two rollers inclined on either side. When the belt is lowered onto the rollers, it is forced into a troughed shape as shown in Fig. 1. This positioning of the rollers influences the load on each of the idlers, with the center roll experiencing a greater force than the two wing rolls [3]. Furthermore, the angle at which the wing rolls are inclined, trough angle, can be adjusted in order to change the shape of the belt and thus the carrying capacity of the belt.

For natural resource sectors such as mining, belt conveyors can be many kilometers in length. Consequently, there can be thousands of idler rollers in use. Idler rollers are responsible for supporting and shaping the belt, which means they experience great forces during their operational lifetime. As such, idlers must be able to withstand significant forces; this has resulted in most idlers being designed with steel shells. While steel idlers have significant structural strength and great performance, their heavy weight is a limitation. 

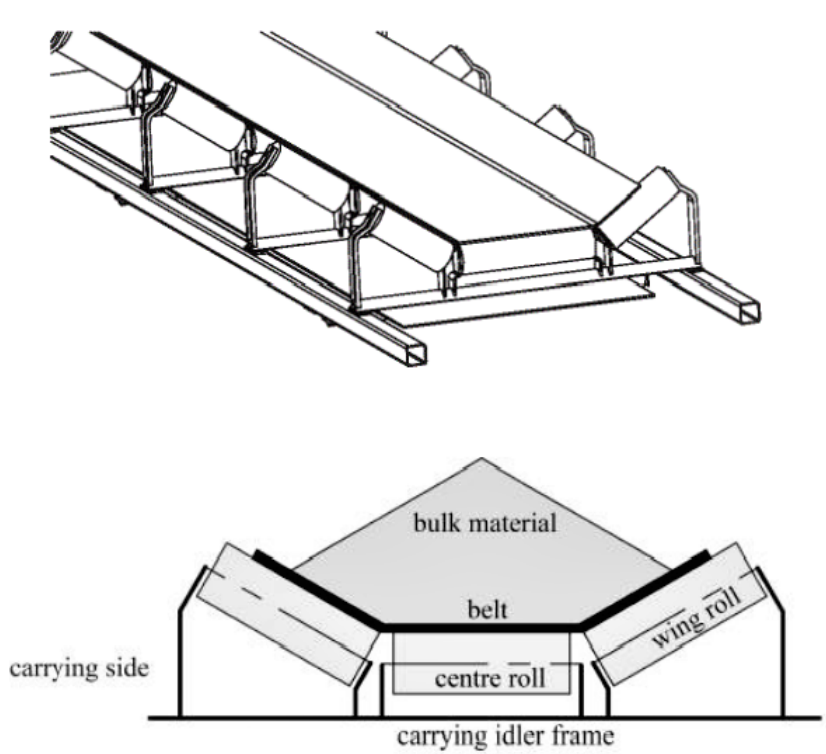

Fig. 1 Troughed belt conveyor [1]

There are two types of idler rollers; carrier idlers that bear the load of the belt and material in the direction of transport, and the return idlers that support the 'empty' belt as it travels toward the tail pulley [2]. The inclusion of these rollers increases the length of the conveyor and the weight of a product that a particular drive can handle [1].

Idler rollers are one of the most critical aspects of any BOR conveyor. Tuckey et al. [5] remarks that the most common cause of breakdowns of belt conveyors is idler failure. The main function of carrier idlers is to support the loaded belt, thus requiring the idlers to be able to withstand great forces. Moreover, noise emission, vibration, speed reliability, and weight are other important considerations when selecting idlers for a conveyor [6].

All idler rollers consist of the same key components; shell, shaft/spindle, bearing, seals, and end cap/bearing housing [6]. Roller shells are documented to be the heaviest component in idler rollers [7]. Currently, the majority of rollers are made out of steel [6], which can range between $19 \mathrm{~kg}$ and $22 \mathrm{~kg}$ for a $330 \mathrm{~mm}$ long roller with a $152 \mathrm{~mm}$ diameter $[8,9]$. For this reason, there is growing demand for light-weight, non-steel rollers in industry. Furthermore, the shaft is the second heaviest component, marking a need to design shaftless rollers.

Composite materials have been proven to be some of the best materials available for extreme applications and environments such as the mining and aerospace industries [10]. Due to their high strength to weight ratio, corrosion resistance, and long service life, composite materials are of great interest for application in many industries. For this project, composite materials with fibres (glass, carbon) embedded in resins (vinyl, epoxy) are of particular interest, initially. However, due to some limitations proposed in Section 2, carbon fiber was excluded from this study.

The methods best suited to manufacturing composite rollers is that of filament winding and roll wrapping. These processes are compatible with many fiber options. This process utilizes a cylindrical mandrel that is rotated, the filaments are coated in the process by running the filament through a resin bath. For applications where the composite is used as a thin shell structure the fibers are often arranged in planar sheets (laminae). The laminae contain parallel fibers that are packed tightly together to provide an isotropic material with a high volume of fibers [10].

A key advantage that has led to the adoption of composite materials in manufacturing is its low weight, yet retaining a rigidity equivalent to that of steel [11]. The company FLEXCO [12] notes that the composite roller design has many advantages over traditional steel rollers. These advantages include a reduction in noise by $10 \mathrm{~dB}$, as well as seeing a power consumption reduction of up to $30 \%$ due to the lower running friction. The authors also note that further advantages include that of corrosion resistance and wear resistance due to the materials low surface friction [12]. Thori et al. [13] also note that other considerable advantages of such composites include that of high chemical stability, low flammability and low toxicity. However, many of these properties depend on the resin that is used for the matrix, as some resins are less heat resistant than others.

Therefore, the focus of this project is the design of a light-weight composite roller with low cost and available materials, that matches the performance of traditional steel rollers. The rest of this paper is organized as follows. In Section 2, loading condition and design process are introduced. In Section 3, experimental results are proposed to show if off the shelf products is a viable option for roller shells. Finally, in Section 5, conclusions are presented.

\section{Design}

Section 2 aims to detail the loadings and analyse the results extracted from Finite Element Analysis (FEA) using ANSYS 18.2.

\subsection{Load case}

The roller is to be analyzed using a troughed configuration, where the load is based on copper ore with a $1.5 \mathrm{~m}$ spacing between each roller. The worst-case scenario is also applied, this being that the full load is taken by the bottom roller, as a centrally applied force. The calculations 
applied to determine the forces are taken from ref [10]. These forces are then used to determine the stub axle diameter using the AS1403-2004 standard [14].

The roller dimensions are attained for a troughed roller set (Series C2 - STIL0900C200) from ref [15] and can be seen in Fig. 2 and Table 1. Knowing the belt width, angle of repose and side troughed roller angle, it is then possible to find the corrected loaded volume $\left(I_{V T}\right)$ using ref [10] which will be $447 \mathrm{~m}^{3} / \mathrm{hr}$.

Then, the loaded volume $\left(I_{m}\right)$ and belt load $\left(I_{V}\right)$ can be calculated as follows:

$I_{m}=I_{V T} \times V=2682 \mathrm{~m}^{3} / \mathrm{hr}$,

$I_{V}=I_{m} \times \rho_{c u}=6436.8$ ton $/ \mathrm{hr}$.

Form these values, the weight of the material per linear meter $\left(q_{g}\right)$ is achieved using the Eq. (3):

$q_{g}=\frac{I_{V}}{3.6 \times V}=298 \mathrm{~kg} / \mathrm{m}$.

For the worst-case loading scenario and $1.5 \mathrm{~m}$ span, the central roller is assumed to take the full force $(F)$ of the loaded belt which acts at the center of the roller (see Fig. 3) and will create the maximum bending moment:

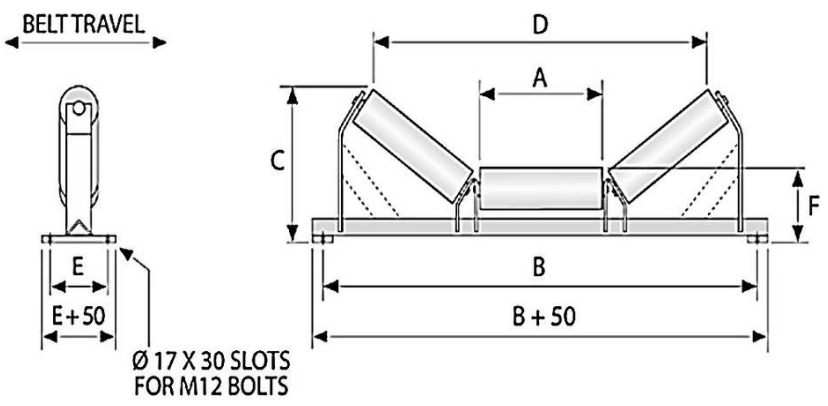

Fig. 2 Troughed roller schematic [15]

Table 1 Troughed roller characteristics

\begin{tabular}{lccc}
\hline Parameter & \multicolumn{3}{c}{ Parameter } \\
\hline A & $331 \mathrm{~mm}$ & Roller outside diameter $\left(D_{0}\right)$ & $152 \mathrm{~mm}$ \\
B & $1150 \mathrm{~mm}$ & Roller trough angle $(\lambda)$ & $30^{\circ}$ \\
C & $397 \mathrm{~mm}$ & Angle of repose $(\beta)$ & $30^{\circ}$ \\
D & $944 \mathrm{~mm}$ & Belt width $(W)$ & $1 \mathrm{~m}$ \\
E & $150 \mathrm{~mm}$ & Belt speed $(V)$ & $6 \mathrm{~m} / \mathrm{s}$ \\
F & & & $1.5 \mathrm{~m}$ \\
Shell & & & \\
thickness $(t)$ & $10 \mathrm{~mm}$ & Roller spacing distance $\left(R_{l}\right)$ & \\
\hline
\end{tabular}

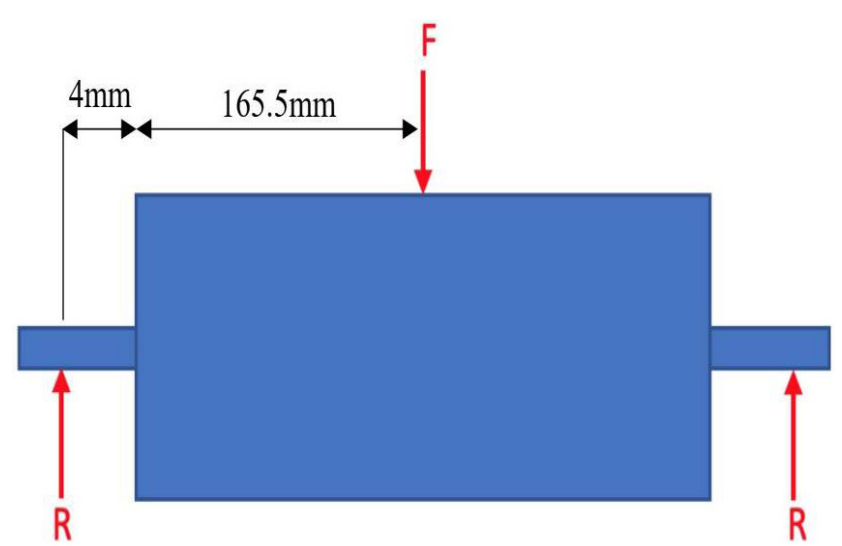

Fig. 3 Roller free body diagram

$F=1.5 \times q_{g} \times g=4384.07 \mathrm{~N}$,

where $g=9.8 \mathrm{~m} / \mathrm{s}^{2}$ is the acceleration of gravity.

The next step is to determine the rollers stub axle diameter $(D)$. To find the diameter, it is first necessary to determine the bending moment on a single stub axle using the maximum bending moment $\left(M_{q, \max }\right)$ :

$M_{q}=\frac{M_{q, \max }}{2}=\frac{L \times F}{2}=372.9 \mathrm{~N} \mathrm{~m}$.

The next value to find is the torque $\left(T_{q}\right)$ acting from the radius of the roller. This is found knowing that the force is to act at the center of the mass of the loaded belt, as the belt section analyzed is $1.5 \mathrm{~m}$ this means that $0.75 \mathrm{~m}$ is overhanging the center of the roller. Assuming the copper ore is distributed evenly over the belt the force is to act in the center of this $0.75 \mathrm{~m}$ overhang, this results in a value of $0.375 \mathrm{~m}$. The torque is determined as follow:

$T_{q}=\frac{q_{g} \times 0.375 \times g}{2} \times \frac{D_{r}}{2}=41.658 \mathrm{~N} \mathrm{~m}$.

The material that the stub axle is to be made out of is grade 431 stainless steel, which has a tensile strength $\left(F_{u}\right)$ of $980 \mathrm{MPa}$. The endurance limit $\left(F_{R}\right)$ is:

$F_{R}=0.45 \times F_{u}=441 \mathrm{MPa}$.

The next value to consider is the safety factor, for the stub axle a safety factor $\left(F_{s}\right)$ of 4 is used. This is to ensure failure of a critical component does not occur.

Using the AS1403-2004 standard [14], the stress raising factor for the stub axle $(K)$ and the bearing $\left(K_{\text {bearing }}\right)$ are 3.38 and 2.4 respectively; and the size factor $\left(K_{s}\right)$ for a $60 \mathrm{~mm}$ for rotating steel shafts is 1.52 . The final variable of axial tensile force $\left(P_{a}\right)$ is also assumed to be 0 as there is no axial loading to the bottom roller.

With all the variables found it is now possible to solve for the minimum required shaft diameter. For more than 
$600 \mathrm{starts} /$ year and 900 revolutions/year, it is calculated by $[10]$ :

$$
D=\sqrt[3]{\frac{10^{4} F_{s}}{F_{R}} K_{s} K \sqrt{\left(M_{q}+\frac{P_{q} D}{8000}\right)^{2}+\frac{3}{4} T_{q}^{2}}}=55.99 \mathrm{~mm} .
$$

As $D$ is less than $60 \mathrm{~mm}$, this means that the shaft diameter of $60 \mathrm{~mm}$ is more than adequate for the stub axle roller design and complies with the AS1403-2004 standard [14].

The next component to evaluate is the shell of the roller, this is to be assessed by determining the deflection of shells made of various materials. These materials include polyethylene, resin epoxy, resin-polyester and epoxy carbon fibre pre-preg. The assumption that the shell is centrally loaded with $F=4.4 \mathrm{kN}$ is used. The first step is to determine the moment of inertia for the shell cross section using Eq. (9):

$I=\pi D_{0}^{3} t=0.000110 \mathrm{~m}^{4}$,

and the deflection $(\delta)$ is:

$\delta=\frac{5 F L^{3}}{384 E I}$,

where $E$ is the Young's modulus of the material and $L$ is the length of the roller. Subbing in the values for the materials results in the deflections results seen in Table 2.

It should be noted that carbon fiber is not considered in this work becuase of the following reasons. The shell constitution faces many prohibiting factors when considering the materials for construction. Of the material tested the carbon fiber shell is by far the most expensive, but the cost does not account for the resin and catalyst required. Another factor that was found to limit the appeal of carbon fiber is a lack of readily available pipe lengths, this pipe option was considered as it would save costs on fabrication and provide an off the shelf component that would require minimum adjustment. However the available commercial sizes are far too small for use as roller shells, both in internal and external diameter.

The stub axle diameter could be decreased by using a different material, however this would limit the rollers

Table 2 Roller shell deflection results

\begin{tabular}{lcc}
\hline Material & $E(\mathrm{GPa})$ & $\delta(\mathrm{mm})$ \\
\hline High Density Polyethylene (HDPE) & 1.1 & 0.005684 \\
Resin epoxy & 3.78 & 0.001654 \\
Resin poly & 3 & 0.002084 \\
Epoxy carbon pre-preg & 91.82 & 0.000068 \\
\hline
\end{tabular}

applications as grade 431 stainless steel provides a high tensile corrosion resistant option. It is also noted that the shell materials tested for deflection all proved effective, with the worst case deflecting $0.005684 \mathrm{~mm}$. As these values are negligible this allows for the cheapest option to be considered. With the considerations of readily available materials, low cost and the results of the deflection calculations (as shown in Table 2) it was decided to use HDPE as the shell material.

\subsection{Design development}

The proposed roller design utilizes key features from previously explored commercially available rollers. These rollers include the CII roller [16] and the design tested by van Rensburg [6].

As shown in Fig. 4, a model of the design was created in SolidWorks and then evaluated using Ansys 18.2; it was simulated under the specified loading condition mentioned in Subsection 2.1.

Two key parameters were considered during the design refinement process; materials and shell thickness. From the literature review, three materials were identified as viable alternatives to steel for use in idler rollers; resin epoxy, resin polyethylene, and High Density Polyethylene (HDPE). Initially, the roller was simulated with varying wall thicknesses for each of the materials. The results were used to determine the minimum wall thickness required to withstand the loading conditions. Then, the endcap/housing material was varied to further reduce the weight of the roller. The dimensions of the roller (except shell wall thickness) and the internal components remained constant. The stub axle was comprised of 431 stainless steel in each design.

The finite element analysis determined that the optimal wall thickness of the shell was $10 \mathrm{~mm}$ for each material. From Table 3, ultimately, the HDPE design was selected

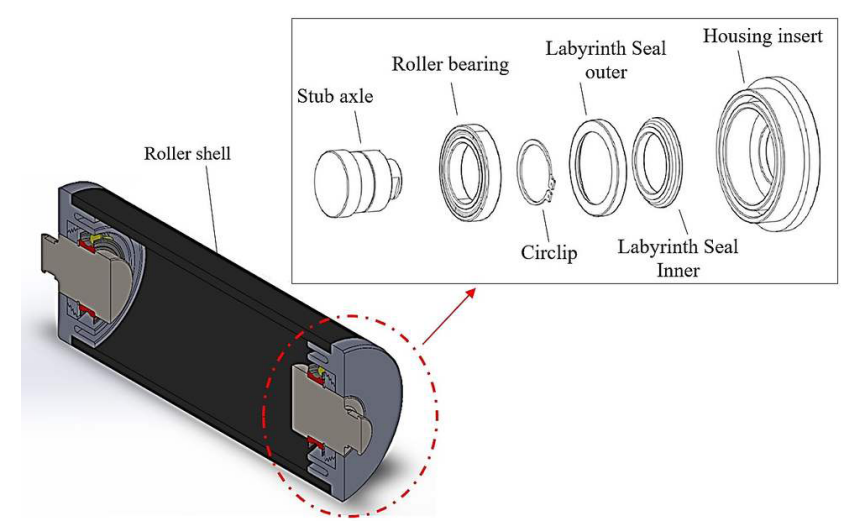

Fig. 4 Prototype shaftless roller (sectional view) 
Table 3 Finite element results for designs with different shell materials

\begin{tabular}{lcccc}
\hline Shell material & Roller mass $(\mathrm{kg})$ & $\begin{array}{c}\text { Weight reduction from } \\
\text { steel roller }(\%)\end{array}$ & $\begin{array}{c}\text { Maximum } \\
\text { deformation }(\mathrm{mm})\end{array}$ & $\begin{array}{c}\text { Maximum stress } \\
(\mathrm{MPa})\end{array}$ \\
\hline Resin epoxy & 11.22 & 45.5 & 0.15 & 37.1 \\
Resin Polyethylene & 11.27 & 45.3 & 0.18 & 38.8 \\
HDPE & 10.94 & 46.9 & 0.46 & 41.7 \\
\hline
\end{tabular}

due to its significant weight reduction from stainless steel rollers of the same size.

In the final design, the roller incorporates an HDPE shell with dimensions $300 \mathrm{~mm}$ long, $152 \mathrm{~mm}$ OD and $10 \mathrm{~mm}$ wall thickness. A stub axle comprised of 431 Stainless Steel is used in place of a full shaft. It should be noted that this substitution significantly decreases the weight of the roller. Off-the shelf bearings, circlips, and seals are utilized in the design in order to reduce the need for additional manufacturing processes. A HDPE endcap is used to shield the internal components from debris.

Preliminary analysis has shown that this design is a suitable light-weight alternative to steel idler rollers. The model estimated that the roller has a mass of approximately $10.9 \mathrm{~kg}$, as opposed to approximately $20.6 \mathrm{~kg}$ for a stainless-steel roller of the same size. Thus, this design is expected to produce a $47 \%$ weight reduction compared to steel rollers.

Under the maximum expected load of $4.4 \mathrm{kN}$, the design was shown to withstand this force. The total deformation profile of the roller is shown below in Fig. 5. As expected, the largest deformation occurs along the section of the shell that the belt sits on. The maximum deformation was estimated to be $0.464 \mathrm{~mm}$ in this section. The endcaps and internal components were shown to have no deformation.

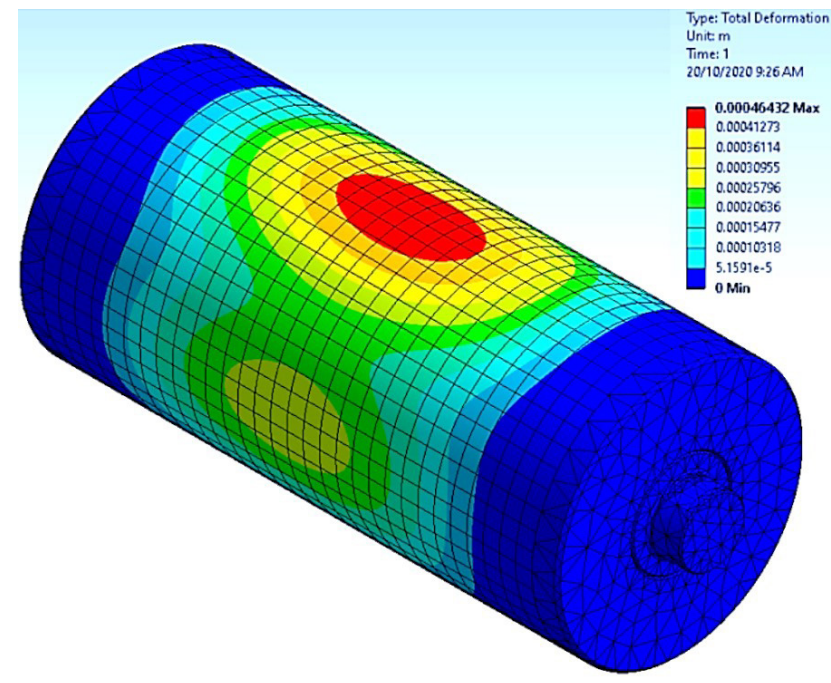

Fig. 5 Total deformation profile
The equivalent stress profile of the roller is shown in Fig. 6. The shell was seen to experience between $642.2 \mathrm{~Pa}$ to $4.6 \mathrm{MPa}$ of stress under the maximum expected load. This is well below the tensile yield strength of HDPE, which is documented to be approximately $26 \mathrm{MPa}$ [17]. Thus, in terms of structural strength, the shell design is a suitable light-weight alternative to steel.

Fig. 7 highlights that the stub axle experiences the largest amount of stress in the roller. This was expected given

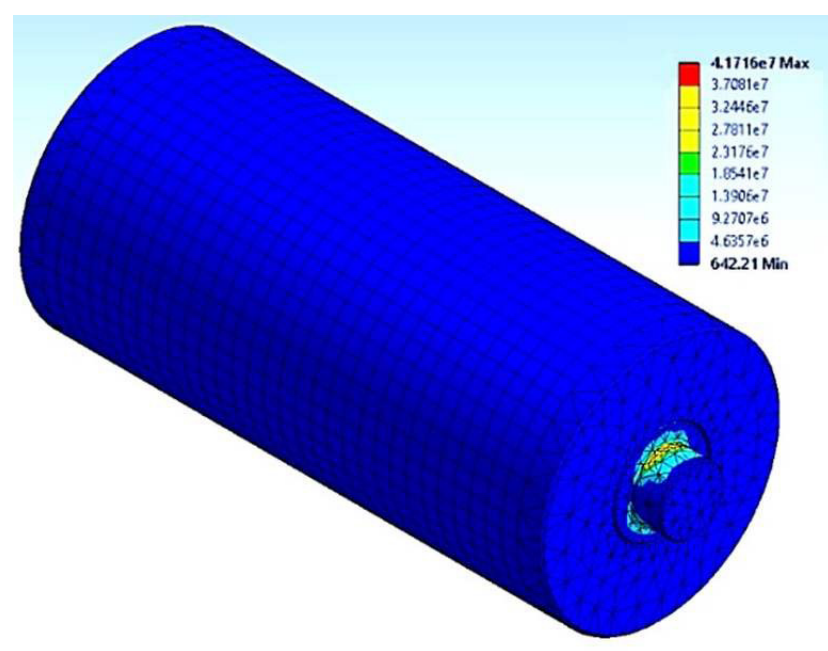

Fig. 6 Equivalent stress profile

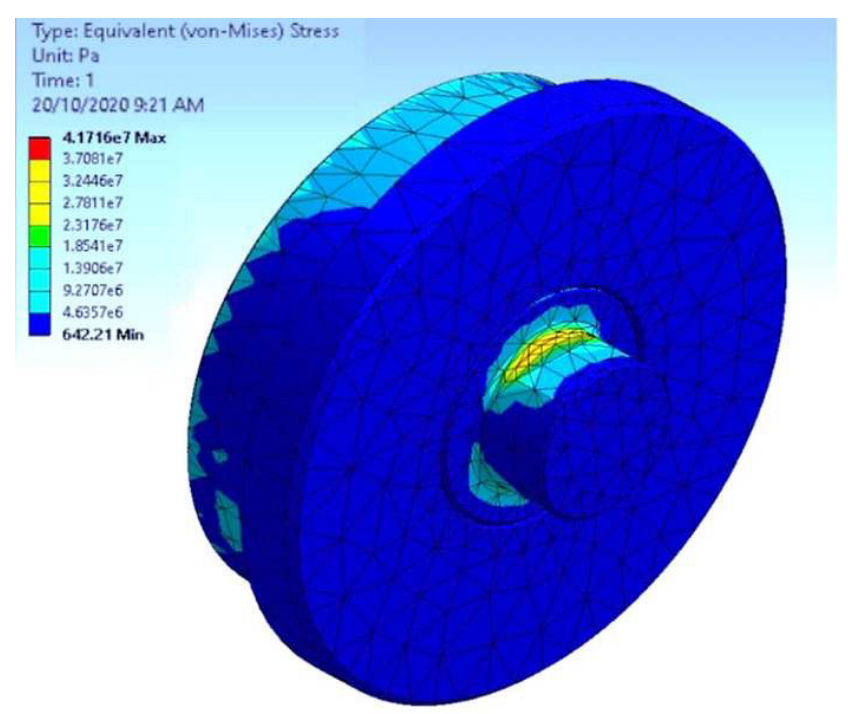

Fig. 7 Equivalent stress profile of endcap and stub axle 
that the axle fixes the roller to the idler frame. Fig. 8 shows a closer look at the stress profile of the stub axle and endcap. The maximum stress was estimated as $41.7 \mathrm{MPa}$, which is well below the tensile yield strength of 431 Stainless Steel $[16,18]$. Thus, it can be expected that the stub axle design is suitable for application in the shaftless roller. However, physical prototyping and testing is required to determine the true performance of the stub axle.

The internal components and HDPE endcap were found to experience increased stress at various points as shown in Fig. 8. The stress in the endcap ranged from 642.2 Pa to approximately $18.5 \mathrm{MPa}$, which is within the tensile yield strength of HDPE. The bearing was found to experience a maximum stress of approximately 18.5 MPa. It is therefore expected that the performance of the internal components and endcap will not be impeded by the loading conditions. Again, prototype testing is required to confirm the performance of the design.

\section{Physical testing}

A test was conducted to determine if off the shelf products would prove to be a viable option as roller shells. This test entailed loading 3 readily available Holman 6" PVC DWV pipe sections compliant to AS/NZS 1477 [19].

These sections were cut to $300 \mathrm{~mm}$ in lengths and the wall thickness was $3 \mathrm{~mm}$. These lengths were then loaded into the Instron testing machine, where a metal plate was added to the bottom and top to evenly disperse the force along the test pieces. The loading configuration can be seen in Fig. 9. The test pieces were gradually loaded up using the Instron with a displacement rate of $0.5 \mathrm{~mm} / \mathrm{s}$, up to $70 \mathrm{~mm}$ displacement. Once this displacement was

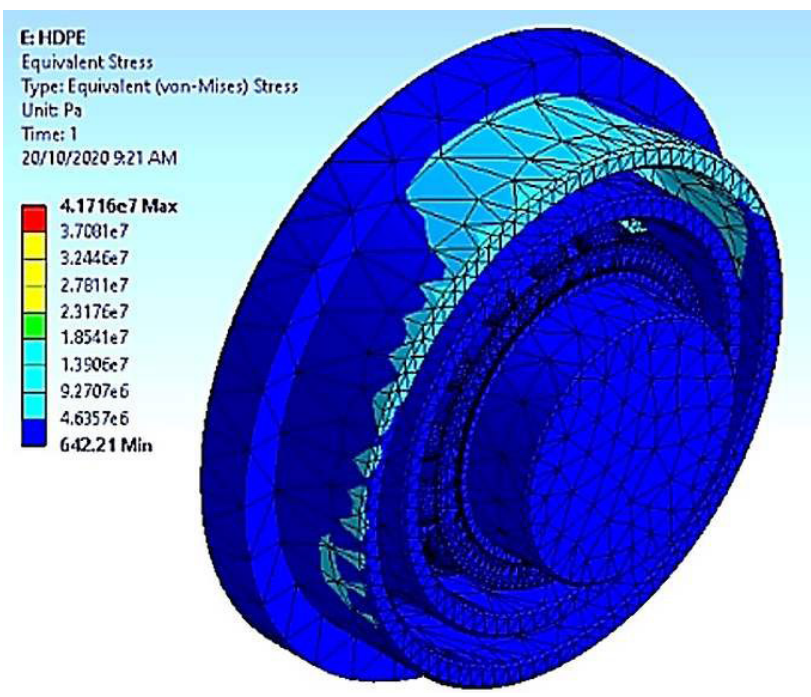

Fig. 8 Equivalent stress profile for endcap and internal components

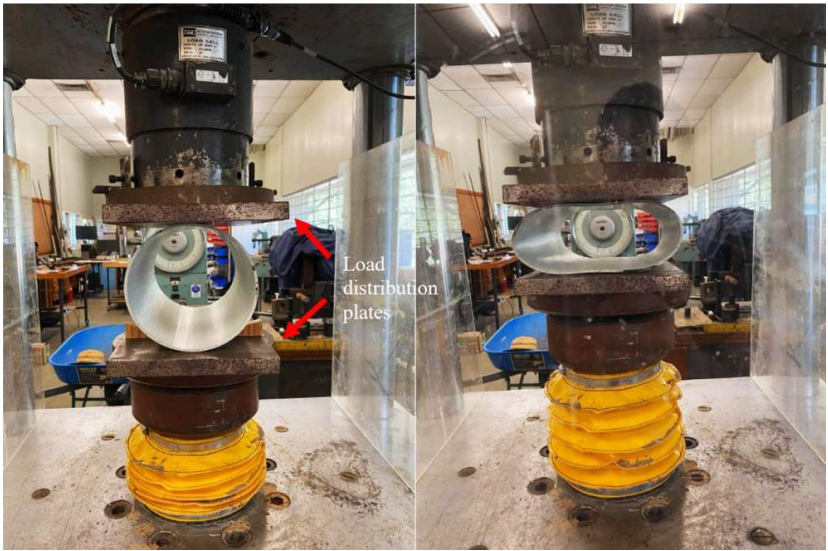

(a)

(b)

Fig. 9 Physical testing: (a) setup; (b) full loading

reached, it was held at this level for a total of $5 \mathrm{~s}$, before being released. This process was repeated for the remaining test pieces. The results for the three tests were plotted against one another and can be seen in Figs. 10 and 11.

These results show that the pipe experiences significant deformation at approximately $2.3 \mathrm{kN}$ of force, which is approximately $52.3 \%$ of the force calculated in the load case summary. The deformation experienced is not plastic and as such returns to its original state when the loading

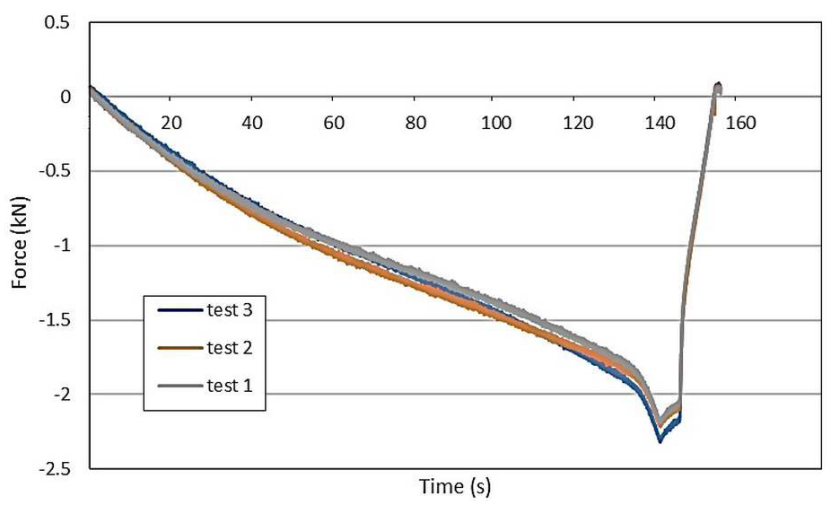

Fig. 10 Axial force - time curve

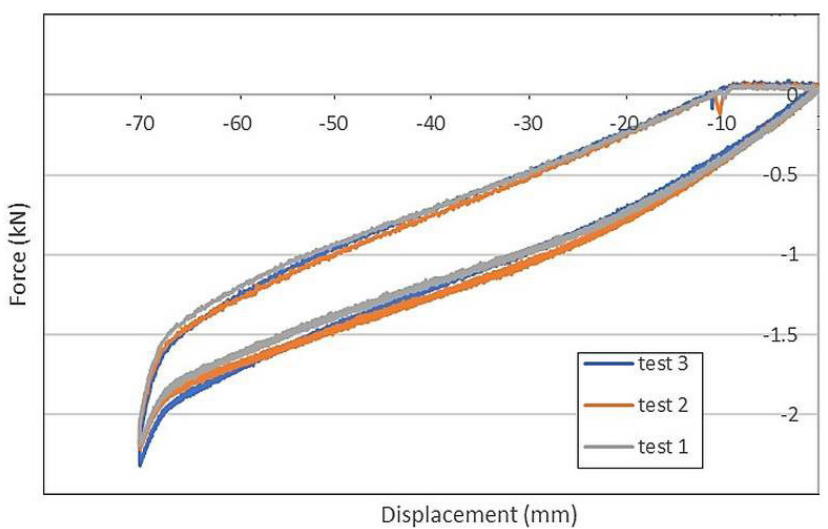

Fig. 11 Axial displacement - axial force curve 
is released. It is noted that the pipe material used is not of the same composition or shell thickness as the one proposed for the prototype, as such further testing is required to provide results that are applicable to the prototype.

The proposed roller design is to utilize as many off the shelf components as possible. This is to reduce manufacturing costs, as well as allow for customers to have access to readily available components should they wish to overhaul the rollers to keep them in service longer. The components and the associated manufacturing processes can be seen in Table 4.

It is noted that the shell material can't be sourced at the exact internal (ID) and external (OD) diameter as an off the shelf part. The closest match is SDR11 PN16 HDPE pipe, which has an OD of $160 \mathrm{~mm}$ and an ID of $130 \mathrm{~mm}$. This means that to attain the sizes required the ID is required to be machined out to $132 \mathrm{~mm}$ and the OD machined down to $152 \mathrm{~mm}$. This process is to be conducted on a lathe, should tungsten carbide bits be used.

\section{Conclusion}

The proposed roller design utilizes key features from previously explored commercially available rollers. Finite Element Analysis (FEA) has shown how the rollers will perform under the identified operational conditions; producing deformation, stress, and strain predictions. It was decided that the stub axle is to be made out of grade 431 stainless steel, this is because it provides a level corrosion resistance whilst having a reasonable tensile strength required for a shaft. With the considerations of available low cost materials and the results of the deflection calculations, it was decided to use HDPE as the shell material. From the FEA it can be seen that the shell experiences greater deformation than the calculated value, though the deformation is not great enough to warrant concern. In addition, the maximum stress occurs on the stub axle is far below the yield point which means that all deformation that may occur is expected to be well within the elastic region, as a result further reinforcing that the stub axle is suitable for the proposed design. The proposed prototype provides a significant reduction in weight of $46.9 \%$ over that of traditional steel rollers of a similar size. Further improvement can be made to the design, some of the proposed design features that could be included in future revisions include the addition of jacking bolt holes in roller insert. This would allow for the insert to be easily extracted from the shell, allowing for the replacement of the bearing and seal should failure occur.

In future work, the focus will be on the investigation of compression behavior of resins and carbon fibre in the design process of shaftless roller.

Table 4 Component manufacturing requirements

\begin{tabular}{|c|c|}
\hline Part name & Manufacturing description \\
\hline Housing insert & CNC machined, composed of Polyethylene \\
\hline Labyrinth seal inner & Off the shelf component \\
\hline Labyrinth seal outer & Off the shelf component \\
\hline Circlip & Off the shelf component \\
\hline Roller bearing & Off the shelf- SKF 6012-2RZ [20] \\
\hline Stub axle & $\mathrm{CNC}$ machined from 431 stainless steel ( $70 \mathrm{~mm}$ diameter) \\
\hline Roller shell & $\begin{array}{l}\text { SDR11 PN16 HDPE pipe [21]: } 160 \mathrm{~mm} \text { OD, } 130 \mathrm{~mm} \text { ID. Machine } 1 \mathrm{~mm} \\
\text { off ID (increase ID from } 130 \mathrm{~mm} \text { to } 132 \mathrm{~mm} \text { ). Machine } 4 \mathrm{~mm} \text { off OD } \\
\text { (decrease OD from } 160 \mathrm{~mm} \text { to } 152 \mathrm{~mm} \text { ). }\end{array}$ \\
\hline
\end{tabular}




\section{References}

[1] McGuire, P. M. "Conveyors: Application, Selection, and Integration", CRC Press, Boca Raton, FL, USA, 2009.

[2] Cooper, D. "Sensor Platform for Monitoring Conveyor Belt Rollers", BSc Thesis, University of Southern Queensland, 2015.

[3] Liu, X. "Prediction of Belt Conveyor Idler Performance", Phd Thesis, Delft University of Technology, 2016.

[4] Woodcock, C. R., Mason, J. S. "Bulk Solids Handling: An Introduction to the Practice and Technology", Springer, Dordrecht, Netherlands, 1987.

https://doi.org/10.1007/978-94-009-2635-6

[5] Tuckey, K., Womach, R., Stolz, H. "Maintenance on Belt Conveyors A Practical Approach to this Vital Link in Continuous Production", In: Proceedings of the International Materials Handling Conference (Beltcon) 3, Johannesburg, South Africa, 1985.

[6] van Rensburg, B. J. "The Development of a Light Weight Composite Conveyor Belt Idler Roller", BSc Thesis, University of Southern Queensland, 2013.

[7] Haines, M. "Development of a conveyor belt idler roller for light weight and low noise", BSc Thesis, University of New South Wales, 2007.

[8] Lorbrand "Idler Catalogue: Specialist designers and manufacturers of heavy duty conveyor components", [pdf] Lorbrand Company, Australia, Available at: https://www.lorbrand.com.au/wp-content/ uploads/2015/12/Lorbrand-Idler-Catalogue.pdf [Accessed: 10 January 2021]

[9] Rexnord "Rex Conveyor Idlers", [pdf] Rexnord Company, USA, Available at: https://www.rexnord.com/contentitems/techlibrary/ documents/6002_catalog [Accessed: 10 January 2021]

[10] Rulmeca "Rollers", [online] Available at: https://www.rulmeca. com/en/products_bulk/catalogue/1/belt_conveying/1/rollers [Accessed: 10 January 2021]

[11] The Japan Carbon Fiber Manufacturers Association "Application to Industrial Fields", [online] Available at: https:/www.carbonfiber.gr.jp/english/field/industrial.html [Accessed: 10 January 2021]

[12] Flexco "Composite rollers", [online] Available at: https://flexco. com.au/EN/Product-Systems/Conveyor-Idlers-and-Rollers/ Composite-Rollers.htm [Accessed: 10 January 2021]
[13] Thori, P., Sharma, P., Bhargava, M. "An Approach of Composite Materials in Industrial Machinery: Advantages, Disadvantages and Applications", International Journal of Research in Engineering and Technology, 2(12), pp. 350-355, 2013.

[14] Standards Australia International "AS1403-2004 Design of rotating steel shafts", Standards Australia International Ltd, Sydney, Australia, 2001.

[15] RKM International Roller Company "Conveyor Idlers and Accessories: World Class Rollers, Idlers, Frames and Structure", [online] Available at: https://rkmrollers.com.au/products/ [Accessed: 10 January 2021]

[16] Marley Pipesystems "HDPE PIPE", [online] Available at: https:// marleypipesystems.co.za/small-bore-hdpe-pipe/ [Accessed: 10 January 2021]

[17] AZO Materials "Stainless Steel - Grade 431 (UNS S43100)", [online] Available at: https://www.azom.com/article.aspx?ArticleID=1023 [Accessed: 10 January 2021]

[18] Interlloy "431 Martensitic Stainless Steel Bar", [online] Available at: http://www.interlloy.com.au/our-products/stainless-steel/431-martensitic-stainless-steel-bar/ [Accessed: 10 January 2021]

[19] Standards Australia, Standards New Zealand "AS/NZS 1477:2017 PVC pipes and fittings for pressure applications", SAI Global Limited, Sydney, 2017. [online] Available at: https://infostore.saiglobal.com/preview/as/as1000/1400/1477-2017.pdf?sku=1916808 [Accessed: 10 January 2021]

[20] "SKF 6012-2RZ Deep groove ballbearings", [online] Available at: https://www.skf.com/group/products/rolling-bearings/ball-bearings/deep-groove-ball-bearings/productid-6012-2RZ [Accessed: 10 January 2021]

[21] "SDR11 PN16 HDPE pipe", [online] Available at: https://www.gfps. com/appgate/ecat/common_flow/1000GX/ID/en/109760/109761/ P560494/product.html [Accessed: 10 January 2021] 